\title{
Notes on the vocalizations of Little Rush-warbler (Bradypterus baboecala)
}

Peter Boesman

In the following we briefly analyze and compare voice of the different races of Little Rushwarbler (Bradypterus baboecala). We also try to quantify the extent of any vocal differences using the criteria proposed by Tobias et al. (2010), as a support for taxonomic review. We have made use of sound recordings available on-line from Xeno Canto (XC).

Typical song is a series of slightly bisyllabic chirruping notes gradually accelerating into a stutter, all at about the same pitch.

Some examples:

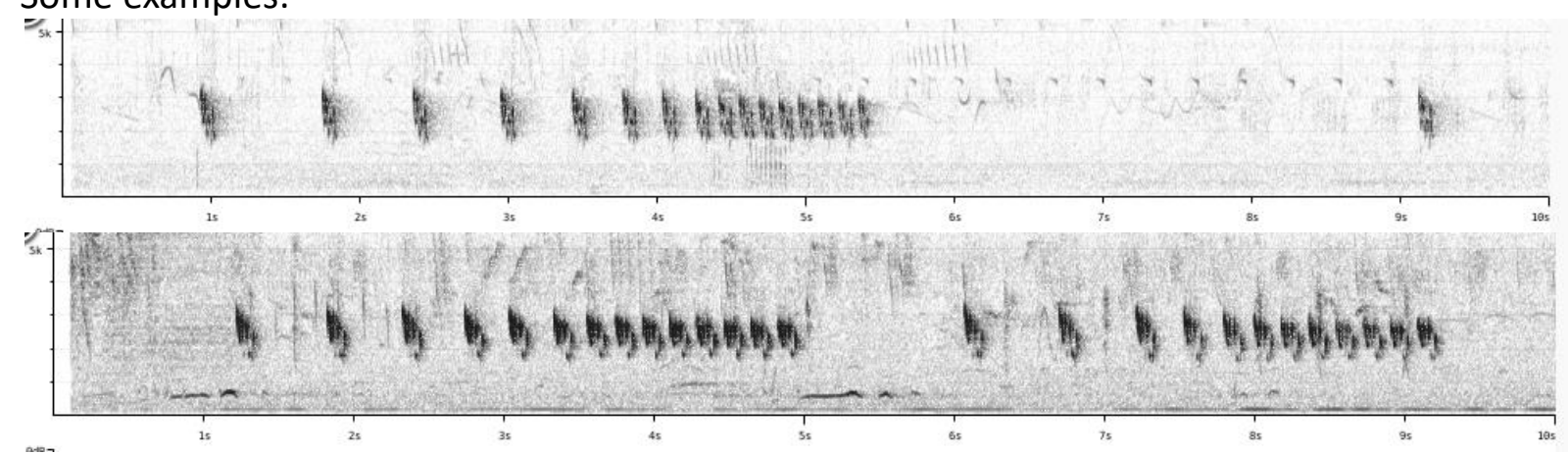

This song has been documented for following races: baboecala, transvaalensis, tongensis, msiri.

Also, centralis in W Africa (Benin, Cameroon):

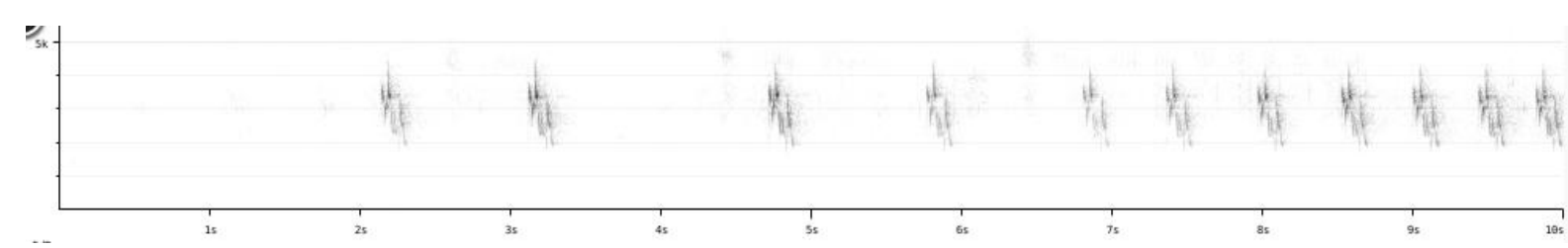

At the other hand, centralis birds from SW Uganda and Rwanda apparently share with elgonensis a much higher-pitched song (repeated notes also much more buzzy than above, and notes slightly decreasing in pitch towards the end):

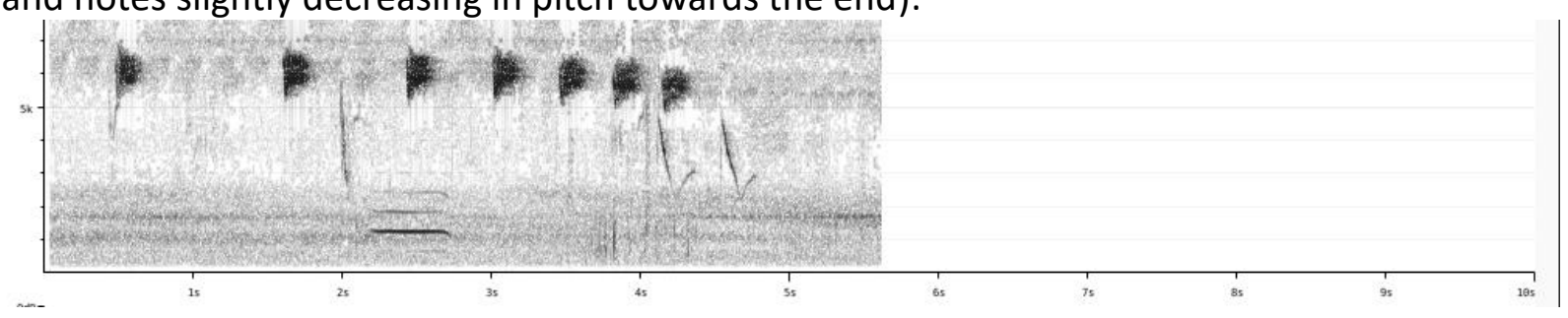

The difference in voice thus apparently does not follow the present subspecific taxonomy based on morphology (with at least centralis likely consisting of two different forms, or western populations rather pertaining to msiri). 


\section{HANDBOOK OF THE

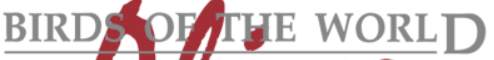 \\ Alve}

\section{ORNITHOLOGICAL NOTES}

In any case, these two song types are very different, and could be given a score of 3 for difference in frequency, 2 for buzzy vs. composed repeated note (quantifiable by number of elements) and 1-2 for pitch change, which would lead to a total vocal score of about 5 when applying Tobias criteria.

If we map where each song type has been found (based on available evidence), we get:

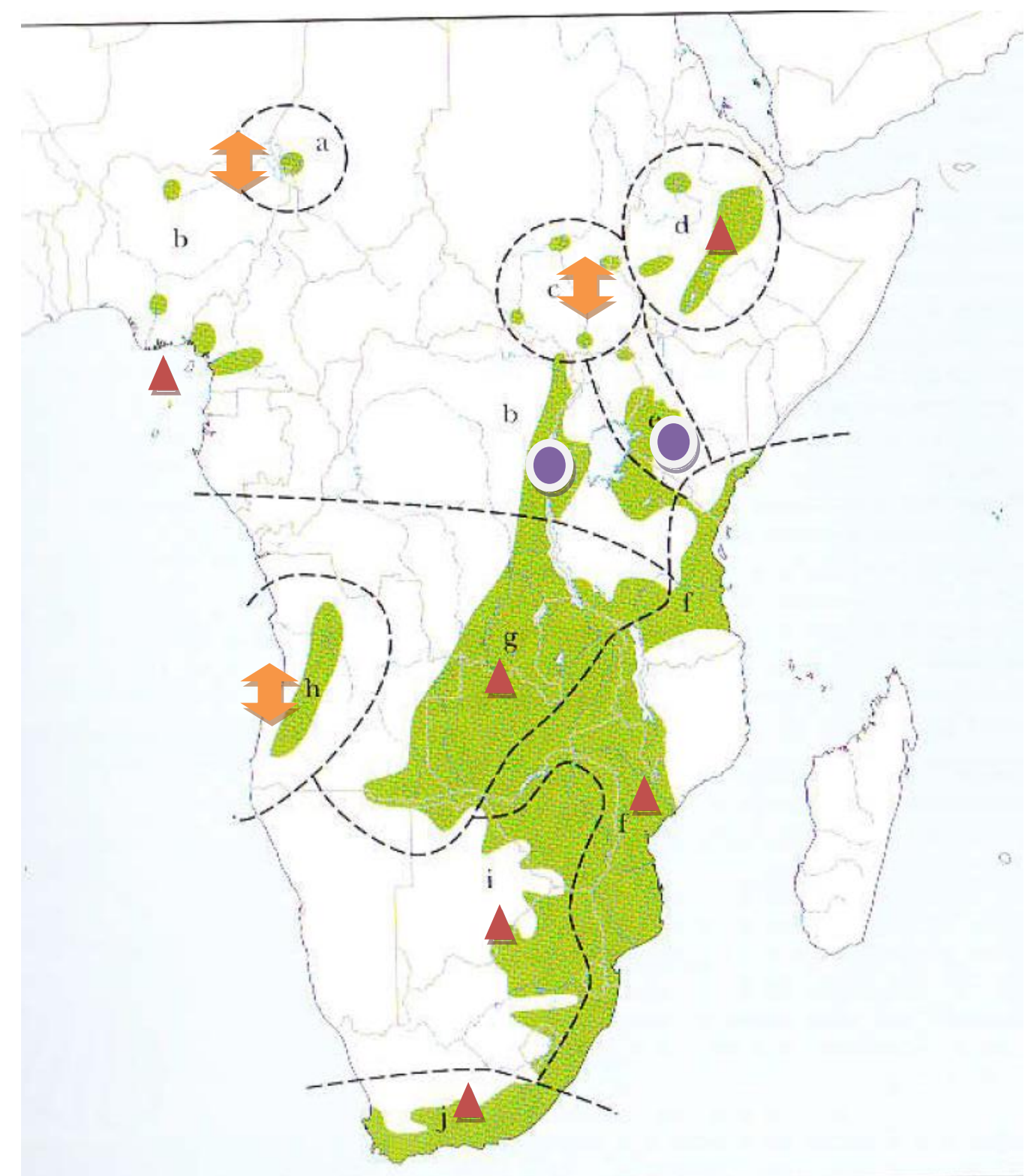

song type $A \quad$ song type $B$

song type unknown

We don't know voice of sudanensis and chadensis. Voice type assignation of abyssinicus is based on Dowsett et al. (2015) (which however seems to contradict Redman et al. (2009). 

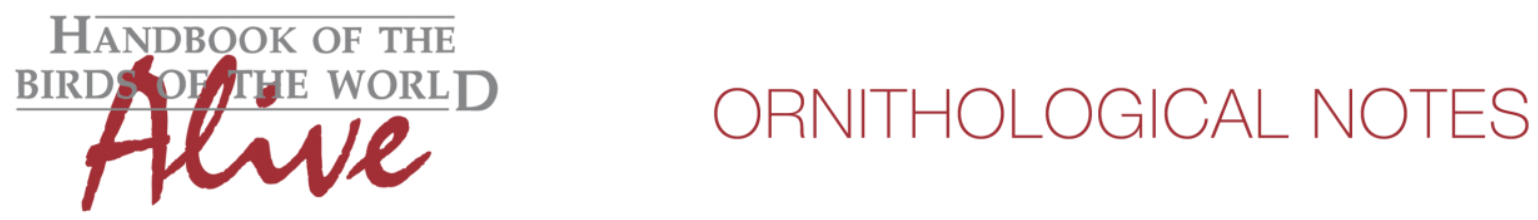

It would thus seem that birds of the song type B are confined to the highland regions around Lake Victoria. More sound recordings of the different populations are however needed to fully understand the distribution of the two song types.

This note was finalized on 15th February 2016, using sound recordings available on-line at that moment. We would like to thank in particular the sound recordists who placed their recordings for this species on XC: Peter Boesman, Sander Bot, Tim Cockcroft, Daniel Danckwerts, Hans Groot, Louis Hansen, Charles Hesse, Faansie Peacock, Bram Piot, Lynette Rudman, Derek Solomon, Martin St-Michel, and Rob van Bemmelen.

\section{References}

Dowsett, R.J. and Dowsett-Lemaire, F. (2015). New avian observations from south-western Ethiopia, with a review of overlooked literature and altitudinal limits. Bull. Brit. Orn. Club 135(3): 224-239.

Redman, N., Stevenson, T. and Fanshawe, J. (2009). Birds of the Horn of Africa. Helm Field Guides. Christopher Helm. London.

Tobias, J.A., Seddon, N., Spottiswoode, C.N., Pilgrim, J.D., Fishpool, L.D.C. \& Collar, N.J. (2010). Quantitative criteria for species delimitation. Ibis 152(4): 724-746.

\section{Recommended citation}

Boesman, P. (2016). Notes on the vocalizations of Little Rush-warbler (Bradypterus baboecala). HBW Alive Ornithological Note 237. In: Handbook of the Birds of the World Alive. Lynx Edicions, Barcelona. (retrieved from http://www.hbw.com/node/932200 on 29 September 2016). 